\title{
Learning What you Really, Really Want: Towards a Conceptual Framework of New Learning in the Digital Work Environment
}

\author{
Julian Decius \\ Paderborn University \\ julian.decius@upb.de
}

\author{
Timo Kortsch \\ Denkverstärker \\ kortsch@denkverstaerker.de
}

\author{
Hilko Paulsen \\ BWZ \\ hilko.paulsen@gmail.com
}

\author{
Anja Schmitz \\ Pforzheim University \\ anja.schmitz@hs-pforzheim.de
}

\begin{abstract}
Digitization and globalization are leading to changing demands in the world of work. To cope with these, employees must constantly learn and develop. Analogous to the New Work movement, the future of learning seems to belong to New Learning, in which protean and empowered learners pursue learning opportunities to achieve subjectively valuable learning outcomes and personal growth. This meaningful and socially-embedded kind of learning enables learners to learn what they really, really want to learn. In the literature, however, there is a lack of models and theories on New Learning. The present paper introduces a conceptual framework of New Learning building on psychological theories in terms of a causal chain whose ten propositions can be empirically examined in future studies. An important premise is that, in addition to personal characteristics of the learner, the sociotechnical environment and (digital) tools and methods play an important role for New Learning. The paper concludes by setting a future research agenda and discussing the practical implications of New Learning.
\end{abstract}

\section{Introduction}

The world of work is changing - not just in recent years, but the pace of change has accelerated throughout the last decades [1]. Technologization, digitalization and globalization shape modern work environments and have an enormous impact on the what, where and how of working. At the same time, questions concerning meaningful work and autonomy gained in importance $[2,3]$. Reflecting these changes, the term New Work has received attention in practice and research. Bergmann [4], taking a critical look at the previous understanding of employment, introduced the term and characterized New Work as needing to contain "work that you really, really want to do." In organizational psychology research, Schermuly [5] picked up on the concept and related New Work to empowerment research [6]. He assumed that psychological empowerment-the experience of meaning, competence, self-determination, and impact-mediates the relationship between New Work activities and positive outcomes for performance and health [5].

It is not only work that is changing, however, but also why and how employees acquire competencies [7, 8]. Continuous and lifelong learning through and for work becomes more important to meet the challenges of the changing world of work [1, 9, 10]. At the organizational level, companies must remain flexible and adaptive to keep pace with global competition; at the personal level, employees must therefore also expand their knowledge to actively shape change and not be replaced by other employees. But the "half time of knowledge" has decreased in recent decades, rendering professional knowledge obsolete more quickly [11]. In addition to training-based formal learning, more flexible learning forms such as informal learning [12] and self-regulated learning [13] thus attracted research attention. Individuals, however, have always been learning informally, through trial and error, feedback, and reflection; or in a self-regulated way through setting their own learning goals, monitoring and regulating the learning process. Thus, just as work is changing into New Work, we assume that learning is also evolving into New Learning. What does New Learning look like, which - in the spirit of Bergmann [4] - emphasizes the autonomous role of the learner but also considers the increasing demands of the volatile world of work?

New in the world of work is, above all, associated with the term "digital". Digitalization offers an incredible number of opportunities to acquire jobrelevant skills. However, digital tools are not sufficient to already speak of New Work [5]. Equally, we cannot reduce New Learning to the use of digital learning tools-learners are part of social groups, and their needs must become the focal point [14]. In the current dynamic and volatile context, organizations do not know-or only with delay_-which learning content is 
needed, and when and where an individual should learn best. It makes sense to shift the decision about the what, when, and where of learning to the entity that has enough information to make a meaningful decision: the learner. If the learner has a high level of autonomy and responsibility, following Bergmann [4], we thus might conceptualize learning what you really, really want as an essential component of New Learning.

However, the term "new" is currently used in an undifferentiated and proliferating manner [5, 15]. Specifically, in the field of learning it lacks a clear conceptualization. We therefore develop a conceptual framework of New Learning to delineate the learning process and influencing variables. We consider $\mathrm{New}$ Learning as a process started by the perception of learning opportunities by empowered learners [6] with a protean career orientation (i.e., an agentic orientation toward their own career [16]). The perception of learning opportunities leads to the formation of a learning intention, which in turn leads to learning behaviors, resulting in learning outcomes. This process is reinforced by the socio-technical work environment - emphasizing the social embeddedness of learning - and respective (digital) work and learning tools, as well as personal attitudes of the learner. These influencing factors are represented as moderators in our framework. We deduct New Learning from Bergmann's [4] socio-philosophical concept of New Work as well as Schermuly's psychological New Work theory, focusing on empowerment. To further specify and extend these approaches, we base our conceptualization of $\mathrm{New}$ Learning on other established psychological theories and models: Theory of Planned Behavior [17], Rubicon Model of Action Phases [18], and Regulatory Focus Theory [19].

Against this background, New Learning refers to learning as a socially-embedded process in which the protean and empowered learner seeks and utilizes learning opportunities to engage in meaningful formal, informal and self-regulated learning to achieve subjectively valuable learning outcomes and personal growth. New Learning takes place in a new societal and organizational context brought forth by digitalization and characterized by dynamic change, uncertainty, and complexity. This definition underscores the importance of balancing social and technological aspects in digital work contexts [20,21].

Our theoretical paper provides for the first time a conceptual psychological framework of New Learning, structured in ten propositions. We set the stage for future empirical research on the concept, which has so far been considered mainly from a practical point of view [14, $15,22]$. We also present a future research agenda that includes possible facilitating factors for New Learning, as well as implications from the model for practice.

\section{Framework Development}

We started the development of our conceptual framework with a literature review for the term "new learning." The search yielded a few practice-based articles, articles from neuropsychological learning research, and frequent use of "new" as a merely descriptive adjective (e.g., new learning challenges). Theoretically sound contributions on the future of learning at work were not present. The search did, however, reveal a first psychologically grounded approach to "new work" [5]. We therefore decided to take the concept of "new work" $[4,5]$ as the starting point for our considerations. In setting up our framework, we therefore followed the basic assumptions that the empowered learner is at the center of learning and learns things he or she wants to learn, rather than primarily following external requirements. Based on these rationales, we sought psychological theories and models that would explain human attitudes, motives, and behaviors in this specific work context. We then established the basic conceptual chain from the new learner's prerequisites to the learning outcomes. Subsequently, strove to identify possible moderators of the specified relationships. This deductive process resulted in ten propositions.

\section{Conceptual Psychological Framework of New Learning}

The following ten propositions form the causal chain of the conceptual psychological framework of New Learning as shown in Figure 1. Each proposition is introduced in sequence below.

Proposition 1. There are two important antecedents of New Learning: protean career orientation and psychological empowerment. High levels of protean career orientation and psychological empowerment increase the potential to perceive learning opportunities. By doing so, they build a formative construct, that we call learning opportunities perception potential (LOPP).

Protean career orientation. The concept of a protean career addresses the employee's long-term development: Hall [23] conceptualized protean career as "a process which the person, not the organization, is managing". Central to this process is "an agentic orientation toward one's career" (p. 201). Individuals differ in their protean career orientation, an attitude that comprises two central facets: self-direction and orientation toward intrinsic values [24]. That is, employees feel responsible for their careers, careerrelated decisions, and actions. Intrinsic values such as 


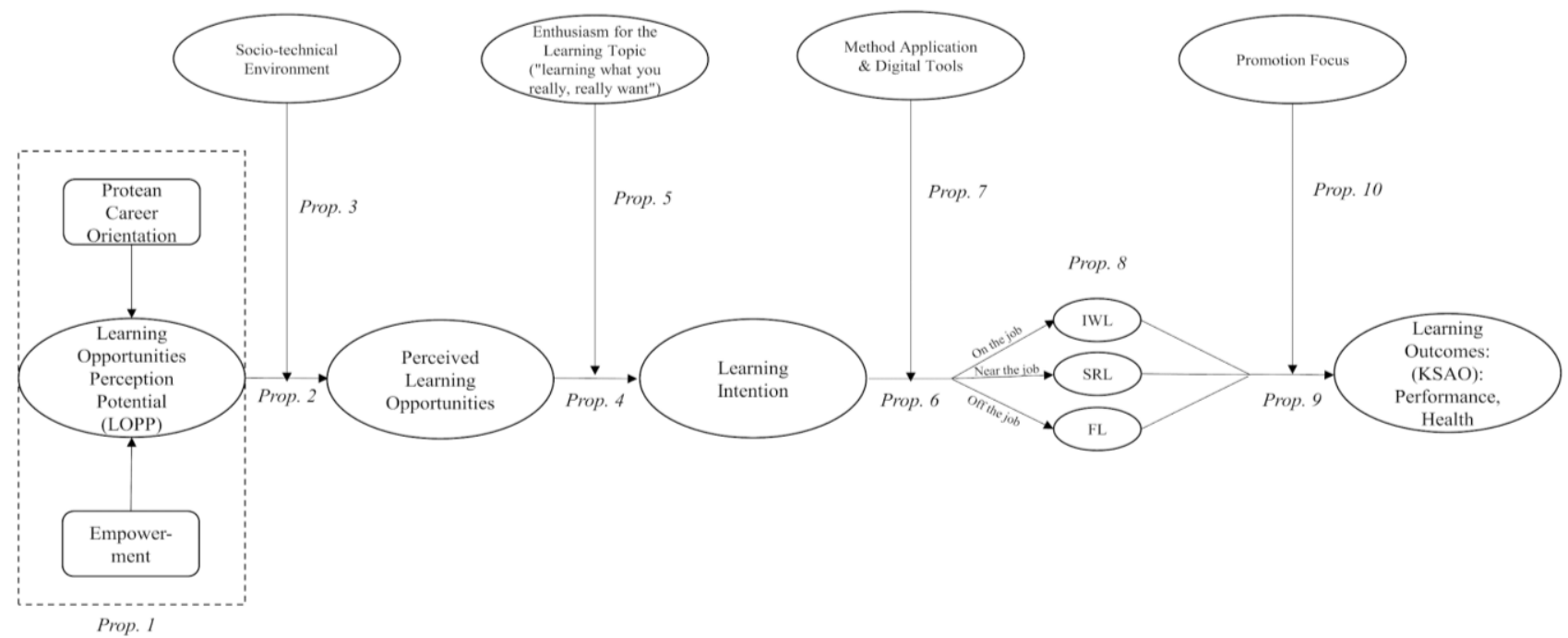

autonomy, meaning and growth guide the career pursuit. Self-direction also results in volition to pursue longterm career goals. High levels of protean career orientation should result in an increased awareness of career development opportunities and employability [25]. These career opportunities may also require learning something [26]. High levels of protean career orientation sharpen the lens through which individuals perceive their environment including its offer of learning opportunities. Consequently, high levels of protean career orientation should increase the LOPP.

Empowerment. While protean career orientation focuses on individual differences, empowerment is rather linked to job characteristics, though it is just a subjective reflection of objective job characteristics [27]. Contrary to a widespread belief, however, New Work is not achieved by organizations equipping their employees with mobile technologies and providing home office facilities. Schermuly [5] notes that sending employees home with a smartphone for paid work is fundamentally

contrary to the understanding and spirit of Bergmann's concept [4] of work-related freedom of choice. In this organization-driven structural empowerment approach, the focus is on the macro level, i.e., on the company's structures. However, since employees interpret their work environment and work processes individually and independently of collective structures [5], the

\section{Figure 1. Conceptual Framework of New Learning}

psychological empowerment approach is preferable for New Work and New Learning. According to Spreitzer [6], this multi-faceted approach includes the facets meaning, competence, self-determination, and impact (see also [28]). Employees with high levels of psychological empowerment perceive their work as

valuable, experience competence and autonomy. So, they may enrich their work with learning opportunities. Consequently, psychological empowerment should increase the potential to perceive learning opportunities.

Proposition 2. It is important to note, that neither protean career orientation nor psychological empowerment provide learning opportunities. Both are personal characteristics that are antecedents of the LOPP. We conceptualize the LOPP as a stable but still malleable personal factor, which serves as a cognitive and motivational filter. This filter shapes the individual's perception within their work environment and helps to identify attractive learning opportunities in specific situations. More specifically, self-direction leads to a proactive seeking for learning opportunities, value orientation leads to recognizing attractive learning opportunities, and empowerment leads to evaluating the feasibility of learning (cf. [6, 29, 30]). A high LOPP increases the probability to recognize learning opportunities - but in a situation without any objective learning opportunities, an individual cannot perceive any learning opportunity. However, in situations with an average amount of learning opportunities, high levels of LOPP will result in high levels of perceived learning opportunities, whereas low levels of LOPP will result in low levels of perceived learning opportunities.

Proposition 3. The socio-technical environment is

an important moderator in the relationship between LOPP and perceived learning opportunities. As described, the LOPP serves as a filter that allows objectively available learning opportunities to become perceived learning opportunities-however, how well this filter works depends not only on the filter quality 
but also on whether it is used in a "filter-friendly" or "filter-hostile" environment. One key aspect of the environment's "filter-friendliness" is the digitalization of work. The higher the digitalization within a sociotechnical system, the higher are learning demands and opportunities. New technologies, for instance, require the acquisition of new skills (cf. [31]). It is important to note that digitalization is by far more than just the usage of new technologies. Digitalization affects the broader socio-technical system and has an impact on organizational structures and processes, and in turn requires new roles from employees $[21,32,33]$. That is, with increased digitalization, working conditions (e. g., complexity, autonomy) and processes will change (e.g., new work tasks) and provide learning opportunities in a broader way. The usage of digital information technology enables collaboration between teams within an organization and beyond organizational structures. However, these changes are just perceived as learning opportunities if LOPP is high. In contrast, in conditions of lower LOPP due to low protean career orientation or a lack of psychological empowerment, the same changes may be appraised as hindering demands rather than opportunities (cf. [34]). The socio-technical environment also comprises social factors such as organizational cultures [35] as well as supervisor and co-worker support. A positive learning culture shapes the values of and basic assumptions about learning and facilitate individual learning [36]. Within organizations that value learning, the link between LOPP and perceived learning opportunities is higher. Supervisor and co-worker support are important environmental factors for learning and application of knowledge in practice [37]. Furthermore, human resource management and its practices influence the perception of learning opportunities [38].

Proposition 4. Perceived learning opportunities make the learner develop a learning intention, i.e., the concrete behavioral intention to engage in learning behavior. Perceived learning opportunities can be considered affordances to learn (cf. [39]), i.e., perceived learning opportunities encourage a person to learn. For example, if someone perceives that coworker support is available and that learning from errors is a desired behavior, they are more likely to learn from them [40]. Following the action phase model, perceived learning opportunities can be assigned to the predecisional phase [18]. Encouraged to learn by a learning opportunity and having formed a concrete learning intention, the learner "crosses the Rubicon". The learner enters the preactional phase, in which it is no longer a question of whether something is learned, but how it is learned.
Proposition 5. As stated before, we assume that the perception of learning opportunities leads to a learning intention. However, the strength of this relationship depends on one important factor: enthusiasm for the learning topic. Building on Bergmann [4] who proclaims in his book on New Work and new culture that the future belongs to work "that we really, really want" (p. 121), in our opinion the future of meaningful learning belongs to learning what you really, really want. This kind of learning does not only satisfy the psychological need for competence but also the need for autonomy, and therefore promotes intrinsic motivation [41]. In other words: The effect of perceived learning opportunities on learning intention is moderated by this enthusiasm for the learning topic. These positively experienced emotions not only push the motivational process of intention formation but can also lead to a positive upward spiral over time as stated in the broaden-and-build theory [42]. That is, enthusiasm for the learning topic fuels learning and growth. Learning, application of what has been learned, and experiencing competence are in turn the basis for increasing enthusiasm for further learning topics.

Proposition 6. According to the Theory of Planned Behavior [17], an intention leads to appropriate behavior when normative beliefs and subjective norms do not interfere, and the individual holds the belief of being able to control the situation. A learner capacitated by the LOPP should have appropriate control beliefs and learning-enhancing values due to protean career orientation and empowerment. Accordingly, learning intention leads to learning behavior. Learning behavior can be defined as follows:

Engagement in mental processes-learning events - that result in the acquisition and retention of knowledge, skills, and/or affect over time and until needed, along with the capacity to identify conditions of performance and respond appropriately. More colloquially, learning is an increased capacity to do the right thing at the right time. (p. 3 [9])

Proposition 7. The relationship between learning intentions and learning behavior is moderated by the availability of tools and learning resources. We assume that a high availability of tools and resources will strengthen the relationship between learning intention and learning behaviors. Digitalization has led to a shift from instruction via conventional media and methods (books, classroom-based lectures, or training) to computer-based media or digital tools [43], such as enterprise social networks, learning experience platforms, search engines, wikis, podcasts, webinars, 
instructional videos, and virtual/augmented reality applications. In digital work environments, these tools can be flexibly accessed by the learner in the moment of need (anytime, anywhere, with any device), point to any content relevant for the learner's current area of interest, or even provide customized feedback through wearables [21, 44, 45]. This access to digital tools as learning resources increases the learner's autonomy and is assumed to consequently facilitate learning behaviors (cf. [46, 47]). When different learning tools and methods are available and easily accessible for learners, learning intent is more likely to result in learning behaviors [48, 49]. New Learning thus manifests itself in empowered learners who use a wide array of available (digital) tools to attain their individual learning goals [14].

Proposition 8. In the preactional phase due to the action phase model [18], the learner's focus is on how to translate the learning intention into behavior. Three pathways can be distinguished in work-related learning contexts, which lead to different learning forms during the subsequent actional phase (cf. [50]): on the job, near the job, and off the job (also known as in work, at work, and outside work [51, 52, 53]).

The "on the job" pathway leads to informal learning behaviors occurring rather casually in the work process (e.g., [12, 46]); the "near the job" pathway leads to learner-planned self-regulated learning (e.g.., [13, 54]), and the "off the job" pathway leads to more structured and planned formal learning or training (e.g., [55, 56]). Below, we describe the three learning forms in more detail.

Formal Learning. Formal learning refers to high structuring in terms of learning context, learning support, learning time, and learning objectives [57]. Formal learning activities are curricular in nature and have a discrete beginning and end [46]. This includes training, instruction, and other formal education. The effectiveness of these activities depends, among other aspects, on the training method chosen, and the skill or task characteristics trained [55]. Despite being highly structured, training interventions should consider individual learner differences, e.g., personality, motivation, and self-efficacy [56].

Informal Learning. According to Decius (2020) [50], work-related informal learning is a conscious learning that takes place independently of external structural constraints and directly at the workplaceusually as a spontaneous reaction to a problem or challenge at work. Accordingly, the learner's intention is directed towards action or problem solving. Even if learning process responsibility and control lie with the learner, an external stimulus determines the goal of action (e.g., an error in the work process). Informal learning occurs outside of formally defined learning contexts or curricula and is characterized by a low degree of planning and organization with respect to learning context, learning support, learning time, and learning objectives [46, 57]. The behavioral facets of informal learning include trying and applying problemsolving strategies, exchange with other people (e.g., obtaining feedback on one's own work performance), and reflection on one's own work performance $[12,58]$.

Self-regulated Learning. Self-regulated learning is "an active, constructive process whereby learners set goals for their learning and then attempt to monitor, regulate, and control their cognition, motivation, and behavior, guided and constrained by their goals and the contextual features in the environment" (p. 453 [54]). Self-regulated learning thus refers to the "modulation of affective, cognitive, and behavioral processes throughout a learning experience to reach a desired level of achievement" (p. 421 [13]). In contrast to informal learning, the learner pursues a self-imposed learning goal that does not have to be triggered by a problem arising in the work process. Accordingly, there is no action intention but an explicit learning intention [50].

In everyday work, often combinations of the above learning forms (i.e., formal, informal, self-regulated) occur. A problem or challenge in the work task, for instance, may lead not only to informal learning but also to the employee requesting and participating in training. However, we consider the presented mapping of learning forms to learning paths (i.e., on the job, near the job, off the job) to be typical. New Learning combines the three learning forms and harnesses their benefits [14].

Proposition 9. Learning behavior leads to various valued outcomes. Learning outcomes refer to the relative permanent change in knowledge, skills, affect and ability as well as other characteristics (KSAO; [9, 59, 60]). Formal as well as informal and self-regulated learning have been shown to lead to positive outcomes on the individual and organizational level $[46,55,59$, $61,62]$. Learning has been shown to be associated with positive work attitudes, knowledge and skill acquisition, and improvements in performance criteria (e.g., job performance, team performance, problem solving, effectiveness, and promotions) $[46,55,56,62]$. Learning helps employees adapt to their work environment and provides them with resources to cope with work demands (e.g., through job crafting, when employees adapt or "craft" the task, relational, or cognitive boundaries of their work; cf. [63]). When workers adapt their work according to their preferences, their learning in turn may improve [64]. We ssume that 
learning is thus also associated with less stress and better health. However, learning opportunities could increase demands in the long-term and therefore result in more strain (e.g., delegated tasks and responsibilities, cf. [65]).

Proposition 10. According to Higgins' [19] Regulatory Focus Theory, a promotion focus is characterized by the individual's striving for positive outcomes. In the New Learning framework, the effect of learning behavior on learning outcomes is reinforced by the promotion focus of the learner as a moderator. If the learner pursues positive outcomes rather than just learning something to avoid negative outcomes (prevention focus), we expect more positive consequences [66, 67]. Aiming for positive outcomes should be more likely if the learner feels enthusiasm about the learning content. Qualitative research has shown that stress and errors enhance learning within the prevention-focus system, whereas positive affect is a typical motivator for the promotion-focus system [68].

\section{Future Research Agenda}

Introducing the conceptual framework of $\mathrm{New}$ Learning we have built on psychological theories leads to further questions that future research could address (see Table 1). These questions can be divided into five areas. The first area encompasses the learning process as an entire chain of effects-here the focus is particularly on triggers and learning behavior (mainly related to proposition 8). The moderators of the relationships can be divided into organizational and personal moderators The former deal with the sociotechnical system (mainly related to proposition 3 ), the latter with the individual characteristics of the learner (mainly related to propositions 5, 6, 7, 10). Research should address how the learning process can be best designed and supported by the organizations and the learners themselves. The fourth area addresses the support provided by (digital) learning methods and tools (mainly related to proposition 7). Finally, the fifth area focuses on learning outcomes, taking into account both the learner's and the organization's perspective (mainly related to proposition 9).

Table 1. A New Learning Research Agenda

\begin{tabular}{|c|c|}
\hline Area & Research Questions \\
\hline $\begin{array}{l}\text { Learning } \\
\text { process }\end{array}$ & $\begin{array}{l}\text { - In which situations or through which triggers does the learner choose which learning } \\
\text { path to follow (i.e., the formal, informal, and self-regulated learning path)? } \\
\text { - How are the different learning forms interrelated? } \\
\text { - Is the learning process linear (as presented in the model) or are there feedback loops } \\
\text { (e.g., "learn crafting" behavior)? }\end{array}$ \\
\hline $\begin{array}{l}\text { Socio-technical } \\
\text { environment/ } \\
\text { organizational } \\
\text { moderators }\end{array}$ & $\begin{array}{l}\text { - Which role does social support play in New Learning compared to traditional learning } \\
\text { - Wontexts? } \\
\text { - Wearning? } \\
\text { - Are there work changes in a socio-technical environment that foster the perception of } \\
\text { learning opportunities in the short-term, but hamper it in the long-term (e.g., does change } \\
\text { lead to less autonomy)? } \\
\text { - Can social support be replaced by technical (robotic) support? } \\
\text { - Which kind of technical or social support (e. g., organizational support, supervisor } \\
\text { support, peer support, feedback and guidance by technical systems) is most important for } \\
\text { the LOPP - learning opportunities relationship? } \\
\text { - How do social and technical support interact? } \\
\text { - How does the quality or quantity of learning opportunities affect their perception? } \\
\text { - Hew Learning enable the alignment of individual and organizational goals? }\end{array}$ \\
\hline
\end{tabular}


Individual characteristics / personal moderators
- Are there additional factors that moderate the relationship between learning intention and learning behavior (e.g., digital competency)?

- Does the prevention focus have a negative effect, no effect at all, or only a less positive effect - compared to the promotion focus - on the relationship between learning behavior and outcomes?

- How does employee tenure affect the relationship between perceived learning opportunities and learning intention?

- Which subjective norms and values, in the sense of the Theory of Planned Behavior, act as most conducive to learning in the context of New Learning?

- How can enthusiasm for learning be awakened?

\begin{tabular}{ll}
\hline Learning tools & Are analog or digital tools better suited to promote New Learning, or is there no \\
difference? & - How do analog and digital tools interact to promote New Learning? \\
- Which affordances of digital tools foster New Learning? & - How effective are learning tools (e.g., learning experience platform) and work tools \\
& (e.g., collaboration software) in promoting New Learning? How do they interact? \\
& - Is there a "Dark Side of Technology" in digital-driven learning that could threaten \\
& learner autonomy? \\
\hline Learning & - Which outcomes are the most important in New Learning (rather knowledge acquisition, \\
outcomes & performance, or health)? \\
& - Is there an adverse impact of New Learning? \\
& - Which outcomes are most important to the learner?
\end{tabular}

\section{Practical Implications, Limitations, and Conclusion}

Our conceptual framework of New Learning has various practical implications at the levels of organizations, teams (with the leaders as particularly relevant team members), and individuals.

At the organizational level, the role of HR departments needs to be further developed. In the spirit of the New Learning model, which considers the learner as the active designer of all learning, the HR department must create its services in a learner-centric way. The HR strategy therefore needs to consider the individual goals of the employees or at least allow a corridor for individual development. Here, the reflection of the current learning culture can delineate this corridor (cf. [14, 36]). The learning culture and the associated basic assumptions (e.g., "learning moves the company forward"), values ("making mistakes is valuable"), and artifacts (e.g., allowing time for learning, providing easily accessible digital and nondigital learning resources, cf. [35]) serve as a guide that makes it clear to employees what learning is desired and what fits the company's strategy. Moreover, a positive learning culture leads to the perception and creation of additional learning opportunities. This can also be a response to the problem that changes resulting from digitization might lead to working conditions that offer fewer opportunities for learning (e.g., high degree of automation, less autonomy).

The team is an important context for $\mathrm{New}$ Learning, since a large part of New Learning takes place in the direct social work environment. Colleagues are often sparring partners or sources of learning, and they can also play a role in the application of methods. It might also be helpful to bring people with similar enthusiasm for learning together in a team so that they can infect each other with their enthusiasm.

From the team in general, leaders stand out as particularly relevant for New Learning. Because leaders act as role models and set the conditions under which learning may occur (cf. [69]) it is important to sensitize managers so that they shape the learning environment of their employees. In addition, leaders 
can empower their employees and thus facilitate $\mathrm{New}$ Learning by giving them meaningful tasks that enable them to experience competence and allow them to make choices $[5,6]$.

At the individual level, the framework suggests that employees have a great deal of control over whether they become New Learners. Here, we can imagine many levers. Learners have the best prerequisites for New Learning if they see their own further development as meaningful and useful for their own goals, can gain meaning from their learning activity, strive for positive results, experience competence, and have autonomy over what they do. Even if this is only fulfilled to some extent, learners could engage in the things they really, really want to do to facilitate learning. The New Learning process can also be strengthened by choosing tools and methods that the learner feels are individually appropriate.

In this paper, we have attempted to define the term New Learning, link it to existing concepts, and conceptualize it within a psychological framework. However, a systematic literature review was not possible due to the ambiguity of the term. Moreover, due to space constraints, we had to limit the present paper to a brief presentation of the relevant theories and mechanisms - we refer interested readers to the cited sources instead. In this sense, we would like this contribution to be understood as a starting point for further research.

Concluding, the presented conceptual framework of New Learning offers a human-centered approach to learning in the digital work environment - a work environment that challenges employees to learn continuously (cf. [21]). A perspective focusing on learner autonomy and enthusiasm is specifically important in digital work contexts where rapid advancements in technology, automation and analytics pose the risk of decreased employee autonomy and control. Our framework provides a building block for creating a more human-centered work design, opening an avenue for digital work contexts to turn into an opportunity for augmenting learning instead of reducing learner autonomy.

\section{References}

[1] Vial, G. (2019). Understanding digital transformation: A review and a research agenda. The Journal of Strategic Information Systems, 28(2), 118-144.

[2] Grant, G. B. (2017). Exploring the Possibility of Peak Individualism, Humanity's Existential Crisis, and an Emerging Age of Purpose. Frontiers in Psychology, 8, 1478.

[3] Bailey, C., Lips-Wiersma, M., Madden, A., Yeoman, R., Thompson, M., \& Chalofsky, N. (2019). The Five
Paradoxes of Meaningful Work: Introduction to the special Issue 'Meaningful Work: Prospects for the 21st Century'. Journal of Management Studies, 56(3), 481499.

[4] Bergmann, F. (2019). New work, new culture: Work we want and a culture that strengthens us. UK: John Hunt Publishing.

[5] Schermuly, C. C. (2019). New Work - Gute Arbeit gestalten: Psychologisches Empowerment von Mitarbeitern [New Work - Designing Good Work: Psychological Empowerment of Employees] (2. Ed.). Freiburg: Haufe.

[6] Spreitzer, G. M. (1995). Psychological empowerment in the workplace: Dimensions, measurement, and validation. Academy of Management Journal, 38(5), $1442-1465$.

[7] Noe, R. A., Clarke, A. D., \& Klein, H. J. (2014). Learning in the twenty-first-century workplace. Annual Review of Organizational Psychology and Organizational Behavior, 1(1), 245-275.

[8] Regan, E., \& Delaney, C. (2011). Brave new workplace: The impact of technology on location and job structures. In M. Malloch, L. Cairns, K. Evans, \& B. N. O'Connor (Eds.), The SAGE handbook of workplace learning (p. 431-442). London: Sage.

[9] Kraiger, K., \& Ford, J. K. (2021). The Science of Workplace Instruction: Learning and Development Applied to Work. Annual Review of Organizational Psychology and Organizational Behavior, 8, 45-72.

[10] Nicolaides, A., \& Poell, R. F. (2020). "The Only Option Is Failure": Growing Safe to Fail Workplaces for Critical Reflection. Advances in Developing Human Resources, 22(3), 264-277.

[11] Arbesman, S. (2013). The half-life of facts: Why everything we know has an expiration date. Penguin.

[12] Decius, J., Schaper, N., \& Seifert, A. (2019). Informal workplace learning: Development and validation of a measure. Human Resource Development Quarterly, 30(4), 495-535.

[13] Sitzmann, T., \& Ely, K. (2011). A meta-analysis of selfregulated learning in work-related training and educational attainment: What we know and where we need to go. Psychological Bulletin, 137(3), 421-442.

[14] Kortsch, T., Decius, J., \& Paulsen, H. (2021). „New Learning": Wie sich das Lernen bei der Arbeit verändert ["New Learning": How learning at work is changing]. Wirtschaftspsychologie aktuell, 2021(1), 44-48.

[15] Foelsing, J., \& Schmitz, A. P. (2021). New Work braucht New Learning [New Work needs New Learning]. Wiesbaden: Springer Gabler.

[16] Hall, D. T., Yip, J., \& Doiron, K. (2018). Protean careers at work: Self-direction and values orientation in psychological success. Annual Review of Organizational Psychology and Organizational Behavior, 5, 129-156.

[17] Ajzen, I. (1991). The theory of planned behavior. Organizational Behavior and Human Decision Processes, 50(2), 179-211.

[18] Heckhausen, H., \& Gollwitzer, P. M. (1987). Thought contents and cognitive functioning in motivational versus 
volitional states of mind. Motivation and Emotion, 11(2), 101-120.

[19] Higgins, E. T. (1997). Beyond pleasure and pain. American Psychologist, 52(12), 1280-1300.

[20] Bennett, E. E. (2014). Introducing New Perspectives on Virtual Human Resource Development. Advances in Developing Human Resources, 16(3), 263-280.

[21] Parker, S. K., \& Grote, G. (2020). Automation, Algorithms, and Beyond: Why Work Design Matters More Than Ever in a Digital World. Applied Psychology: An International Review (online first).

[22] Hagen New Learning Manifesto (2021). Retrieved from https://www.fernuni-hagen.de/english/university/hagenmanifesto.shtml [last access: 01.06.2021].

[23] Hall, D. T. (1976). Careers in organizations. Glenview, IL: Scott, Foresman.

[24] Gubler, M., Arnold, J., \& Coombs, C. (2014). Reassessing the protean career concept: Empirical findings, conceptual components, and measurement. Journal of Organizational Behavior, 35(1), 23-40.

[25] Lin, Y. (2015). Are you a protean talent? The influence of protean career attitude, learning-goal orientation and perceived internal and external employability. The Career Development International, 20(7), 753-772.

[26] Van Der Heijden, B., Boon, J., Van der Klink, M., \& Meijs, E. (2009). Employability enhancement through formal and informal learning: an empirical study among Dutch non-academic university staff members.

International Journal of Training and Development, 13(1), 19-37.

[27] Spreitzer, G. M., Cameron, L., \& Garrett, L. (2017). Alternative work arrangements: Two images of the new world of work. Annual Review of Organizational Psychology and Organizational Behavior, 4, 473-499.

[28] Thomas, K. W., \& Velthouse, B. A. (1990). Cognitive elements of empowerment: An "interpretive" model of intrinsic task motivation. Academy of Management Review, 15(4), 666-681.

[29] Gijbels, D., Raemdonck, I., \& Vervecken, D. (2010). Influencing work-related learning: The role of job characteristics and self-directed learning orientation in part-time vocational education. Vocations and Learning, 3(3), 239-255.

[30] Hirschi, A., Jaensch, V. K., \& Herrmann, A. (2017). Protean career orientation, vocational identity, and selfefficacy: An empirical clarification of their relationship. European Journal of Work and Organizational Psychology, 26(2), 208-220.

[31] Van Laar, E., van Deursen, A. J., van Dijk, J. A., \& de Haan, J. (2020). Determinants of 21st-century skills and 21 st-century digital skills for workers: A systematic literature review. Sage Open, 10(1), 215824401990017.

[32] Strohmeier, S. (2020). Digital human resource management: A conceptual clarification. German Journal of Human Resource Management, 34(3), 345365.

[33] Trenerry, B., Chng, S., Wang, Y., Suhaila, Z. S., Lim, S. S., Lu, H. Y., \& Oh, P. H. (2021). Preparing Workplaces for Digital Transformation: An Integrative Review and
Framework of Multi-Level Factors. Frontiers in Psychology, 12, 620766.

[34] Meyer, S. C., \& Hünefeld, L. (2018). Challenging cognitive demands at work, related working conditions, and employee well-being. International Journal of Environmental Research and Public Health, 15(12), 2911.

[35] Schein, E. H. (2010). Organizational culture and leadership (Vol. 2). John Wiley, \& Sons.

[36] Kortsch, T., \& Kauffeld, S. (2019). Validation of a German Version of the Dimensions of the Learning Organization Questionnaire (DLOQ) in German Craft Companies. Zeitschrift für Arbeits- und Organisationspsychologie A\&O, 63(1), 15-31.

[37] Botke, J. A., Jansen, P. G., Khapova, S. N., \& Tims, M. (2018). Work factors influencing the transfer stages of soft skills training: A literature review. Educational Research Review, 24, 130-147.

[38] Bednall, T. C., \& Sanders, K. (2017). Do opportunities for formal learning stimulate follow-up participation in informal learning? A three-wave study. Human Resource Management, 56(5), 803-820.

[39] Gibson, J. J. (2014). The Ecological Approach to Visual Perception: Classic Edition. London; New York: Psychology Press.

[40] Decius, J., Schaper, N., \& Seifert, A. (2021). Work Characteristics or Workers' Characteristics? An InputProcess-Output Perspective on Informal Workplace Learning of Blue-Collar Workers. Vocations and Learning, 14(2), 285-326.

[41] Ryan, R.M., \& Deci, E. L. (2000). Self-determination theory and the facilitation of intrinsic motivation, social development, and well-being. American Psychologist, 55(1), 68-78.

[42] Fredrickson, B. L. (2001). The role of positive emotions in positive psychology: The broaden-and-build theory of positive emotions. American Psychologist, 56(3), 218.

[43] Mayer, R. E. (2019). Thirty years of research on online learning. Applied Cognitive Psychology, 33(2), 152-159.

[44] Cojocariu, V.-M., Lazar, I., Nedeff, V., \& Lazar, G. (2014). SWOT Analysis of E-learning Educational Services from the Perspective of their Beneficiaries. Procedia - Social and Behavioral Sciences, 116, 19992003.

[45] Gegenfurtner, A., Schmidt-Hertha, B., \& Lewis, P. (2020). Digital technologies in training and adult education. International Journal of Training and Development, 24(1), 1-4.

[46] Cerasoli, C. P., Alliger, G. M., Donsbach, J. S., Mathieu, J. E., Tannenbaum, S. I., \& Orvis, K. A. (2018). Antecedents and outcomes of informal learning behaviors: A meta-analysis. Journal of Business and Psychology, 33(2), 203-230.

[47] Damnik, G., Proske, A., Narciss, S., \& Körndle, H. (2013). Informal learning with technology: The effects of self-constructing externalizations. Journal of Educational Research, 106(6), 431-440.

[48] Hurtz, G. M., \& Williams, K. J. (2009). Attitudinal and motivational antecedents of participation in voluntary 
employee development activities. Journal of Applied Psychology, 94(3), 635-653.

[49] Maurer, T. J., Barbeite, F. G., \& Mitchell, D. R. D. (2002). Predictors of attitudes toward a 360-degree feedback system and involvement in post-feedback management development activity. Journal of Occupational, \& Organizational Psychology, 75(1),

[50] Decius, J. (2020). Informelles Lernen im Kontext industrieller Arbeit - Konzeptualisierung, Operationalisierung, Antezedenzien und Lernergebnisse [Informal learning within the context of industrial work: Conceptualization, operationalization, antecedents, and learning outcomes]. Paderborn University.

[51] Jacobs, R. L., \& Park, Y. (2009). A proposed conceptual framework of workplace learning: Implications for theory development and research in human resource development. Human Resource Development Review, 8(2), 133-150.

[52] Kyndt, E., \& Beausaert, S. (2017). How do conditions known to foster learning in the workplace differ across occupations? In J. E. Ellingson \& R. A. Noe (Eds.), Autonomous learning in the workplace (p. 201-218). New York: Routledge.

[53] Sambrook, S. (2005). Factors influencing the context and process of work-related learning: Synthesizing findings from two research projects. Human Resource Development International, 8(1), 101-119.

[54] Pintrich, P. R. (2000). The role of goal orientation in selfregulated learning. In M. Boekaerts, P. R. Pintrich \& M. Zeidner (Eds.), Handbook of self-regulated learning ( $\mathrm{p}$. 451-502). San Diego: Academic Press.

[55] Arthur, W., JR., Bennett, W., JR., Edens, P. S., \& Bell, S. T. (2003). Effectiveness of training in organizations: A meta-analysis of design and evaluation features. Journal of Applied Psychology, 88(2), 234-245.

[56] Ford, J. K., Baldwin, T. T., \& Prasad, J. (2018). Transfer of Training: The Known and the Unknown. Annual Review of Organizational Psychology and Organizational Behavior, 5(1), 201-225.

[57] Kyndt, E., \& Baert, H. (2013). Antecedents of Employees' Involvement in Work-Related Learning: A Systematic Review. Review of Educational Research, 83(2), 273-313.

[58] Tannenbaum, S. I., Beard, R. L., McNall, L. A. \& Salas, E. (2010). Informal Learning and Development in Organizations. In S. W. J. Kozlowski \& E. Salas (Eds.), Learning, training, and development in organizations ( $\mathrm{p}$. 303-332). New York: Routledge.

[59] Baldwin, T. T., Kevin Ford, J., \& Blume, B. D. (2017). The State of Transfer of Training Research: Moving Toward More Consumer-Centric Inquiry. Human Resource Development Quarterly, 28(1), 17-28.

[60] Kraiger, K., Ford, J. K., \& Salas, E. (1993). Application of cognitive, skill-based, and affective theories of learning outcomes to new methods of training evaluation. Journal of Applied Psychology, 78(2), 311-328.

[61] Blume, B. D., Ford, J. K., Baldwin, T. T., \& Huang, J. L. (2010). Transfer of training: A meta-analytic review. Journal of Management, 36(4), 1065-1105.
[62] Tynjälä, P. (2013). Toward a 3-P Model of Workplace Learning: A Literature Review. Vocations and Learning, 6(1), 11-36.

[63] Bakker, A. B., \& Demerouti, E. (2018). Multiple levels in job demands-resources theory: Implications for employee well-being and performance. In E. Diener, S. Oishi, \& L. Tay (Eds.), Handbook of well-being. Noba Scholar.

[64] Van Ruysseveldt, J., van Wiggen-Valkenburg, T., \& van Dam, K. (2021). The self-initiated work adjustment for learning scale: development and validation. Journal of Managerial Psychology (online first).

[65] De Lange, A. H., Taris, T. W., Jansen, P., Kompier, M. A., Houtman, I. L., \& Bongers, P. M. (2010). On the relationships among work characteristics and learningrelated behavior: Does age matter? Journal of Organizational Behavior, 31(7), 925-950.

[66] Lanaj, K., Chang, C. H., \& Johnson, R. E. (2012). Regulatory focus and work-related outcomes: a review and meta-analysis. Psychological Bulletin, 138(5), 9981034.

[67] Wolfson, M. A., Tannenbaum, S. I., Mathieu, J. E. \& Maynard, M. T. (2018). A cross-level investigation of informal field-based learning and performance improvements. Journal of Applied Psychology, 103(1), 14-36.

[68] Federman, J. E. (2020). Regulatory focus and learning. European Journal of Training and Development, 44(4/5), 425-447.

[69] Hannah, S. T., \& Lester, P. B. (2009). A multilevel approach to building and leading learning organizations. The Leadership Quarterly, 20(1), 34-48. 